\title{
PAPEL DO ENFERMEIRO NA PREVENÇÃO DAS DOENÇAS PERIODONTAIS E SAÚDE BUCAL DURANTE PRÉ-NATAL
}

\section{ARTIGO ORIGINAL}

AHLSTEDT, Jessy Morganna ${ }^{1}$

VASQUES, Jeane Bonfim ${ }^{2}$

GUEDES, Claudia ${ }^{3}$

AHLSTEDT, Jessy Morganna. VASQUES, Jeane Bonfim. GUEDES, Claudia. Papel do Enfermeiro na prevenção das doenças periodontais e saúde bucal durante pré-natal. Revista Científica Multidisciplinar Núcleo do Conhecimento. Ano 05, Ed. 11, Vol. 16, pp. 137-147. Novembro de 2020. ISSN: 2448-0959, Link de acesso: https://www.nucleodoconhecimento.com.br/saude/prevencao-das-doencas

\section{RESUMO}

A pesquisa aborda a importância do enfermeiro na consulta de pré-natal para prevenção de doenças periodontais e saúde bucal das gestantes. O objetivo geral da pesquisa é reconhecer a importância do enfermeiro na prevenção das doenças periodontais e na saúde bucal de gestantes em consulta pré-natal. Tem como objetivos específicos: a) Identificar as doenças periodontais que atingem as gestantes;

b) Descrever as consequências das doenças periodontais para as gestantes e o feto; e c) Discutir a função do enfermeiro na consulta pré-natal à luz das políticas públicas

1 Pós graduando em Enfermagem Obstétrica (Estácio de Sá), Classificadora e Auditora em Manchester - 2017/2020 (GBCR), Bacharel em Enfermagem - 2017 (UNITRI).

${ }^{2}$ Orientadora. Mestrado em Educação. Especialização em Enfermagem em Unidade de Terapia Intensiva. Graduação em Enfermagem e Obstetrícia.

${ }^{3}$ Orientadora. 
vigentes no país. O presente artigo será desenvolvido com base em uma pesquisa de campo, descritiva, qual quantitativa, realizada na cidade de Uberlândia-MG no ano de 2017, onde foi utilizada como instrumentos de coleta de dados do grupo, uma entrevista semiestruturada realizada com a população de gestantes atendidas em consultas de pré-natal das referidas unidades: Unidades Básicas de Saúde da Família UBSF Jardim Célia I e II, UBSF Morumbi I e II, UBSF Joana Darc I e II na cidade de Uberlândia, que realizam consulta pré-natal;

Palavras-Chave: Cuidado pré-natal, Doença Periodontal, Educação em Saúde, Enfermagem, Gravidez.

\section{INTRODUÇÃO}

O presente artigo destaca a importância do início precoce do pré-natal para também junto com outros exames de rotinas sejam realizados pelos enfermeiros a avaliação da saúde bucal, exame que não é só de responsabilidade do profissional odontólogo, mas também de competência do enfermeiro na tentativa de prevenir sob orientações de uma higiene oral regular e correta, e também diagnosticar possíveis problemas periodontais já existentes, encaminhando essa mulher para um dentista o mais cedo possível para minimizar as conseqüências para ela e para o feto.

O estudo abrange as principais doenças periodontais baseadas em estudo de revisão literária, que podem ser diagnosticadas também durante o período gestacional, informar os principais sintomas e consequências para a mulher e para o feto, e destacar o papel do enfermeiro na prevenção das doenças periodontais e na promoção da saúde bucal.

Baseado em uma pesquisa de campo previa, a qual tinha como objetivo geral de reconhecer a importância do papel do enfermeiro na prevenção das doenças periodontais e na saúde bucal de gestantes em consulta pré-natal. E como objetivos específicos: a) Identificar as doenças periodontais que atingem as gestantes; b) Descrever as consequências das doenças periodontais para as gestantes e o feto; $\mathrm{e}$ 
c) Discutir a função do enfermeiro na consulta pré-natal à luz das políticas públicas vigentes no país.

O atual estudo trás as análises da pesquisa anterior na tentativa de ilustrar a realidade da saúde pública na cidade onde a pesquisa foi realizada, servindo como fonte de informações e como subsídio para futuras pesquisas na área.

No intuito de alertar os profissionais de enfermagem sobre a importância de uma melhor avaliação bucal durante as consultas de pré-natal, identificando precocemente as doenças para evitar complicações para as gestantes e para o feto.

$\mathrm{Na}$ tentativa de sensibilizar os enfermeiros que realizam pré-natal de que é imprescindível a busca por cursos de atualização em saúde bucal, para melhorar a assistência prestada no exame físico bucal das gestantes aumentando assim a capacidade de diagnóstico e orientação na prevenção de doenças periodontais.

Este estudo se justifica pelo fato de possibilitar uma melhora nas condições de saúde e qualidade da assistência prestada às gestantes durante as consultas de pré-natal, no sentido de que será um alerta aos profissionais de Enfermagem sobre a real importância de uma avaliação bucal integral.

\section{METODOLOGIA}

Este estudo trata-se de um recorte dos resultados de uma pesquisa de campo realizada para o Trabalho de Conclusão de Curso (TCC), apresentado ao Centro Universitário do Triângulo no Curso de Enfermagem, no ano 2017. A pesquisa intitulada "O papel do enfermeiro na prevenção das doenças periodontais e na saúde bucal de gestantes em consulta pré-natal em Uberlândia", obteve a aprovação do CEP sob o número do parecer 2.061.249.

Pesquisa com Survey, com o objetivo de obter dados ou informações sobre características de um determinado grupo de pessoas utilizando-se de um instrumento de pesquisa (FONSECA, 2002) do tipo descritiva, caracteriza determinado fenômeno, população ou estabelece relações entre variáveis, exploratória, tem por finalidade 
esclarecer, desenvolver e modificar ideias e conceitos permitindo formular hipóteses pesquisáveis para estudos posteriores e formar problemas mais precisos e explicativos, identificar os fatores que contribuem ou determinam a ocorrência de fenômeno (GIL, 2008) de cunho qualitativa, hierarquiza as ações de descrever, compreender, explicar e buscar resultados os mais fidedignos possíveis (GERHARDT; SILVEIRA, 2009) e quantitativa, centrada na objetividade, recorre à linguagem matemática para descrever as relações entre variáveis (FONSECA, 2002).

O estudo foi realizado com clientes atendidos nas unidades UBSF Jardim Célia I e II, UBSF Morumbi I e II, UBSF Joana Darc I e II na cidade de Uberlândia-MG, durante o período de 22 de maio a 2 de junho de 2017.

A amostra foi composta por um grupo de gestantes no segundo trimestre de gestação, clientes das Unidades Básicas de Saúde da Família: UBSF Jardim Célia I e II, UBSF Morumbi I e II, UBSF Joana Darc I e II na cidade de Uberlândia, que participam de consultas de pré-natal.

O levantamento de dados foi realizado após aprovação do estudo pelo CEP/UNITRI. A obtenção de dados do grupo foi por meio de entrevista realizada por uma das pesquisadoras com o intuito de se conhecer o grau de conhecimento das gestantes quanto à importância de se prevenir doenças periodontais.

O referido instrumento de coleta de dados foi aplicado pela acadêmica co-autora do projeto de pesquisa, por meio de visitas diárias às Unidades Básicas de Saúde da Família: UBSF Jardim Célia I e II, UBSF Morumbi I e II, UBSF Joana Darc I e II no período de 22 de maio a 2 de junho de 2017.

As clientes foram abordadas pela pesquisadora do projeto durante seu período de espera para realizar sua consulta pré-natal, em sala reservada disponibilizada pela própria unidade, após explicações procedimentos metodológicos adotados (assinatura do Termo de Consentimento Livre e Esclarecido), a pesquisadora aplicou os instrumentos de coleta de dados. 
Os critérios de inclusão foram os seguintes requisitos: gestantes no segundo trimestre de gestação, clientes das Unidades Básicas de Saúde da Família: UBSF Jardim Célia I e II, UBSF Morumbi I e II, UBSF Joana Darc I e II na cidade de Uberlândia-MG;

\section{RESULTADOS E DISCUSSÃO}

Em relação à classificação das gestantes entrevistadas nas UBSF (57\%) se considera da cor parda, 30\% branca e 13\% negra, a maior porcentagem de gestantes entrevistadas possui o ensino médio completo (34\%), seguido pelo ensino fundamental incompleto $(23 \%)$, ensino médio incompleto (20\%), superior incompleto (7\%) e apenas $3 \%$ possuem superior completo. $63 \%$ possuem uma renda familiar de até dois salários-mínimos, 30\% informaram que a renda familiar é menor que um salário-mínimo e 7\% disseram ter uma renda familiar entre 2 e 4 salários-mínimos. A faixa etária de 20 e 24 anos (30\%), e entre 25 e 29 anos (30\%) são iguais, seguido pela alta porcentagem (20\%) de adolescentes entre 15 e 19 anos. A maioria (43\%) está no terceiro trimestre de gestação, seguido por $34 \%$ de gestantes no segundo trimestre e $23 \%$ de gestantes no primeiro trimestre. Como critério de exclusão as gestantes no primeiro e terceiro trimestre não continuaram a entrevista.

Das gestantes que se encontravam no segundo trimestre de gestação a metade informou ser a primeira gravidez, sendo que todas disseram não ter tido problemas periodontais na(s) gestação(ções) anteriores, mas $20 \%$ das gestantes realizaram tratamento periodontico na(s) gestação(ções) anterior(es), discordando da afirmação anterior. $40 \%$ das gestantes entrevistadas esta ou teve alguma doença periodontal na gestação atual, sendo que (50\%) que tiveram problemas periodontais informou estar ou ter tido sangramento gengival durante a gestação atual, $25 \%$ ter sido diagnosticada com gengivite, e $25 \%$ com outras doenças periodontais. Apenas $30 \%$ das gestantes realizaram algum tratamento periodontal durante a gestação atual. $60 \%$ das gestantes entrevistadas tiveram alguma doença periodontal antes da gestação, das quais $67 \%$ informaram ter tido cárie e as outras 33\% outras doenças periodontais. Uma alta porcentagem de gestantes (90\%) informou não ter recebido avaliação bucal pela enfermeira durante a consulta de pré-natal, a maioria das gestantes $(60 \%)$ entrevistadas disse não ter recebido nenhuma orientação referente à saúde bucal, 
metade das gestantes informou ter tido consulta odontológica agendada durante o pré-natal, $(50 \%)$ relatou insatisfação em relação ao cuidado bucal recebido durante o pré-natal, e apenas $30 \%$ de satisfeitas.

Com o resultado da pesquisa fica evidente a falta de integralidade em relação à assistência prestada pelos profissionais de enfermagem durante as consultas de prénatal, já que o profissional se limita a gestação, e não realiza uma anamnese completa incluindo a avaliação através do exame físico da condição da higiene oral daquela paciente, deixando passar esse momento como sugere a promoção da saúde (REIS et al., 2007 apud SILVEIRA; ABRAHAM; FERNADES, 2016).

Sendo a segunda patologia mais prevalente no mundo, a doença periodontal pode acometer cerca de 30 a $100 \%$ de pacientes do gênero feminino durante a gestação (NAVES et al, 2009 apud RIBEIRO, 2013). Devido a essa alta porcentagem é indispensável que o enfermeiro, durante a consulta de pré-natal, fique atento para possíveis sinais que possam indicar alguma doença periodontal mesmo que a paciente não relate nenhum sintoma.

Assim como as outras patologias, as doenças periodontais devem ser diagnosticadas e tratadas o quanto antes possível, para evitar desconfortos na gestante e problemas no feto, como prematuridade e baixo peso.

As doenças periodontais podem ser silenciosas passando despercebidas nas consultas de pré-natal, fazendo com que as gestantes só procurem atendimento odontológico quando os sintomas mais graves e incômodos aparecerem, atrasando o tratamento e aumentando as chances de complicações para a gestante e para o feto.

Com base em estudos é possível correlacionar eventos adversos da gestação com periodontite (PAPAPANOU; LINDHE, 2011 apud SILVEIRA; ABRAHAM; FERNADES, 2016; GOEPERT, 2004 et al apud SILVEIRA; ABRAHAM; FERNADES, 2016). Pois as bacteremias transitórias comuns as reações inflamatórias nas gengivas associadas à má higiene oral e a conseqüente formação de placa bacteriana, por via 
hematogênica podem atingir fluidos amnióticos afetando tecidos materno-fetais (RITTER; SOUTHERLAND, 2007 apud SILVEIRA; ABRAHAM; FERNADES, 2016).

Quando a placa bacteriana se limita a gengiva é diagnosticada como gengivite, mas quando o processo inflamatório atinge a estrutura de sustentação dos dentes é denominado periodontite, essa última pode causar perda óssea irreversível (SILVEIRA; ABRAHAM; FERNADES, 2016).

A gengivite é a doença periodontal mais freqüente atingindo mais de $30 \%$ das gestantes (LÖE e SILNESS, 1963 apud BERTOLINI et al, 2007). É necessário que o enfermeiro perceba através dos exames físicos oral nas gestantes possíveis sinais de uma provável gengivite, e encaminhe a gestante para uma consulta odontológica o quanto antes.

A cárie é um dos problemas de saúde que pode atingir as gestantes, essa elevação de caries nas gestantes está relacionada à má higiene oral, a episódios recorrentes de vômitos, alterações dos hábitos alimentares e no aumento do número de refeições (REIS, 2007).

Cabe ao enfermeiro orientar as gestantes quanto à importância da higiene oral na prevenção da carie, ressaltando o uso da escovação dos dentes, língua e uso do fio dental sempre após as refeições.

Outro problema que pode ocorrer em menos de $10 \%$ das gestantes é o granuloma gravídico ou tumor gravídico, associado a uma intensa resposta inflamatória do tecido gengival à placa bacteriana. (HILL, 1998 apud PASSANEZI; BRUNETTI e SANT'ANA, 2007).

O enfermeiro deverá encaminhar a gestante para avaliação odontológica para decidir se o tratamento durante a gestação é necessária, não devendo ser negligenciada com medo de colocar a saúde do feto em risco, pois o atendimento odontológico é seguro, principalmente a partir do $2^{\circ}$ trimestre de gestação, devendo o tratamento adequado ser discutido entre a equipe da atenção básica visando um melhor tratamento para 
aquela paciente que passa por uma fase tão singular na vida (RITTER; SOUTHERLAND, 2007 apud SILVEIRA; ABRAHAM; FERNADES, 2016).

As consequências das alterações hormonais na saúde bucal durante a gestação muitas vezes são desconhecidas pelos próprios profissionais, favorecendo o aparecimento de doenças periodontais, causando prejuízo na qualidade da assistência prestada ao pré-natal.

As mudanças fisiológicas e variações hormonais que interferem na resposta imunológica da gestante podem repercutir na homeostase bucal (HONKALA e ALANSARI, 2005 apud VENANCIO et al, 2011).

Essa alteração na homeostase bucal da gestante é causada por elevadas taxas de estrógeno que parece ser responsável pela diminuição da ceratinização e aumento do glicogênio no epitélio gengival, reduzindo a efetividade da defesa que a barreira epitelial desempenha no organismo (DAVENPORT et al., 1998 apud PASSANEZi; BRUNETTI e SANT'ANA, 2007).

E o aumento da progesterona favorece a dilatação dos micros vasos gengival tornando os mais suscetíveis a injuria e exsudação (MACPHEE e COWLEY, 1975 apud PASSANEZi; BRUNETTİ e SANT'ANA, 2007).

Essas alterações hormonais durante a gestação podem comprometer a saúde bucal da gestante, sendo necessário um melhor cuidado com a higiene oral, assim é de grande importância que o enfermeiro a oriente sobre essas alterações e a incentive a melhorar a higienização oral.

A falta de informação das gestantes em relação aos cuidados em saúde bucal é um dos motivos que contribui para a falta de busca da assistência odontológica durante o período gravídico, essa evidencia demonstra a necessidade de intervenções em nível primário de atenção à saúde focando na educação coletiva (VIEİRA e ZOCRATTO, 2007 apud PEIXOTO et al, 2011). 
É indispensável que as unidades de saúde realizem grupos de gestantes com temas que abordem os cuidados da saúde bucal durante a gestação, falando sobre as principais doenças periodontais que podem acometer as gestantes, deixando clara a necessidade de uma melhor higienização oral durante o período gravídico na tentativa de diminuir os impactos causados no bem estar das gestantes e nas possíveis consequências para o feto.

Cabe ao profissional enfermeiro durante as consultas de pré-natais uma avaliação integral da mulher, e não se prender somente a procedimentos técnicos específicos e fragmentados, mas sim ampliando a sua capacidade de percepção daquela mulher além da gestação em si, melhorando o seu atendimento aquela paciente.

Durante as consultas é possível orientar as gestantes sobre os cuidados com a higiene oral adequada durante a gravidez, explicando os possíveis sinais e sintomas de prováveis doenças periodontais que podem aparecer nessa fase, e já introduzir as orientações de higiene oral do recém-nascido. Pois se sabe que a mulher nesta fase esta suscetível a informações, modificações e aquisição de novos hábitos em prol da saúde do bebê (REIS et al, 2007 apud SILVEIRA; ABRAHAM; FERNADES, 2016).

Além dos problemas causados na gestante, as doenças periodontais podem comprometer a saúde do feto trazendo várias complicações.

A ocorrência de abortos espontâneos e de aproximadamente $11 \%$ de prematuridade no Brasil pode ser associada a doenças periodontais. Sendo que as doenças periodontais atinjam com maior incidência a população de baixa renda e escolaridade. Afirma-se que o gênero, o poder socioeconômico, o nível de escolaridade e a qualidade da vida conjugal são fatores determinantes da condição periodontal (CASTRO et al, 2005 apud RIBEIRO, 2013; TRENTIN et al, 2007 apud RIBEIRO, 2013). 


\section{CONSIDERAÇÕES FINAIS}

É preciso que os enfermeiros se conscientizem sobre a importância de uma boa avaliação da cavidade oral das gestantes, tanto para a gestante quanto para o feto. Fazendo a prevenção por meio de exame físico em todas as consultas de pré-natais, e realizando a promoção da saúde bucal através de explicações simples para que a gestante possa entender as consequências para ela e para o feto caso ela não realize uma boa higienização oral e não consulte regularmente com um dentista.

Os objetivos propostos na pesquisa foram alcançados sendo eles, reconhecer a importância do papel do enfermeiro na prevenção das doenças periodontais e na saúde bucal de gestantes em consulta pré-natal; identificar as doenças periodontais que atingem as gestantes; descrever as doenças periodontais mais comuns nas gestantes e suas consequências para o feto; identificar a função do enfermeiro na consulta pré-natal.

Levando-se em conta o que foi observado durante a pesquisa, nota-se uma grande insatisfação por parte das gestantes em relação ao cuidado bucal recebido durante o pré-natal, provavelmente relacionado ao despreparo profissional das enfermeiras em relação ao conhecimento dos problemas periodontais, seus sinais e sintomas, suas consequências tanto para a gestante como para o feto. É necessária a implantação do tema na grade curricular do curso superior de Enfermagem, para que os futuros formandos recebam esse conhecimento ainda durante o período acadêmico da faculdade, e para os profissionais que já atuam em consulta de pré-natal faz-se necessário a participação em cursos de especialização relacionados à saúde bucal.

\section{REFERENCIAS}

BERTOLINI, P.F.R; BIONDI FILHO, O; NIERO, B. G; SARACENI, C. H. C; SPLENDORE, S. M. G; POMÍLIO, A; GUANAIS, M. A. B. Medicina periodontal e a mulher: a importância do seu conhecimento para uma abordagem preventiva por ginecologistas/obstetras e cirurgiões-dentistas. Rev. Ciênc. Méd., Campinas, 16(3):175-185, maio/junho, 2007. Disponível em:<http://periodicos.puc- 
Campinas.edu.br/seer/index.php/cienciasmedicas/article/view/1060> Acesso em: 11/09/2016.

FONSECA, J. J. S. Metodologia da pesquisa científica. Apostila. UEC, Fortaleza- CE, 2002. $127 \mathrm{p}$.

GERHARDT, T. E; SILVEIRA, D. T. Métodos de Pesquisa. Rio Grande do Sul: Editora UFRGS, 2009. 32 p.

GIL, A.C. Métodos e Técnicas de Pesquisa Social. 6ª Edição. São Paulo: Editora Atlas S.A, 2008. 47p.

PASSANEZI, E; BRUNETTI, M.C; SANT'ANA, A. C. P. Interação entre a doença periodontal e a gravidez. Revista Periodontia, (Jun 2007) V. 17 №2 p 32-38. Disponível em:<www.revistasobrape.com.br/arquivos/junho2007/artigo4.pdf>. Acesso em 10/08/2016.

PEIXOTO, C. R; FREITAS, L. V; TELES, L. M. R; CAMPOS, F. C; PAULA, P. F; DAMASCENO, A. K. C. O pré-natal na atenção primária: o ponto de partida para reorganização da assistência obstétrica. Rev. enferm. UERJ, Rio de Janeiro, 2011 abr/jun; 19(2):286-91.Disponível em :<http://www.facenf.uerj.br/v19n2/v19n2a19.pdf>. Acesso em: 09/10/2016.

REIS, D. M. PITTA, D. R; FERREIRA, H. M. B; JESUS, M. C. PMORAES, M. E. L; SOARES, M. G. S. Educação em saúde como estratégia de promoção de saúde bucal em gestantes. Ciência \& Saúde Coletiva, 15(1):269-276, 2010. Disponível em:<http://www.scielosp.org/pdf/csc/v15n1/a32v15n1.pdf>. Acesso em:10/09/2016.

RIBEIRO, C.M. Relação entre doença periodontal em gestantes com parto prematuro e o nascimento de bebês de baixo peso. Revista Saúde e Desenvolvimento vol.4, n.2, jul/dez, $2013 . \quad$ Disponível em:<http://www.grupouninter.com.br/revistasaude/index.php/saudeDesenvolvimento/ article/view/223/195> Acesso em: 11/09/2016. 
SILVEIRA, J. L. G. C; ABRAHAM, M. W; FERNANDES, C. H. Gestação e saúde bucal: significado do cuidado em saúde bucal por gestantes não aderentes ao tratamento. Rev. APS. 2016 out/dez; 19(4): 568 - 574. Disponível em: < http://ojs2.ufjf.emnuvens.com.br/aps/article/view/15657/8201>. Acesso em: 28/04/2019.

VENANCIO, E. Q; PAULA, E. M. Q. V; IMADA, S. R;REIS, C. B. A percepção do enfermeiro da saúde da família sobre saúde bucal na gestação. CiencCuidSaude, 2011; 10(4):812-819. Disponível em: <periodicos.uem.br/ojs/index.php/CiencCuidSaude/article/download/18327/pdf>. Acesso em: 09/10/2016.

Enviado: Julho, 2020.

Aprovado: Novembro, 2020. 